\title{
Heats of Transformations in Bismuth Oxide by Differential Thermal Analysis
}

\author{
Ernest M. Levin and Clyde L. McDaniel
}

(January 5, 1965)

\begin{abstract}
DTA was chosen as a convenient method for resolving differences in the reported heat of transition and heat of fusion of $\mathrm{Bi}_{2} \mathrm{O}_{3}$. The heat of the low to high transition of $\mathrm{K}_{2} \mathrm{SO}_{4}\left(\right.$ at $\left.583{ }^{\circ} \mathrm{C}\right)$ and the heat of fusion of $\mathrm{Ag}$ (at $960.8{ }^{\circ} \mathrm{C}$ ) were used as internal standards. These standards were mixed directly with the $\mathrm{Bi}_{2} \mathrm{O}_{3}$ in three weight ratios. The heating schedule for each weight ratio was $3^{\circ} / \mathrm{min}, 9^{\circ} / \mathrm{min}$, and $3 \% \mathrm{~min}$. For evaluating internal consistency, DTA determinations were made for mixtures of the two standards. Linearity was obtained within limits between the weight ratio of $\mathrm{Bi}_{2} \mathrm{O}_{3}$ and standard and the corresponding ratio of peak areas. The heat of transition of $\mathrm{Bi}_{2} \mathrm{O}_{3}$ (mon $\stackrel{730}{\rightarrow}{ }^{\circ}$ cubic was found to be $9.9 \pm 0.5 \mathrm{kcal} / \mathrm{mole}$ and the heat of fusion (cubic $\stackrel{825}{\rightarrow}{ }^{\circ}$ liq.) $3.9 \pm 0.2 \mathrm{kcal} / \mathrm{mole}$. The uncertainties are estimated limits of error, based on internal consistency and on the values of the standards.
\end{abstract}

\section{Introduction}

By application of the Clausius-Clapeyron equation to the liquidus curve of the $\mathrm{Bi}_{2} \mathrm{O}_{3}-\mathrm{PbO}$ system $[1],{ }^{1} \mathrm{~K}$. K. Kelley determined the heat of fusion of $\mathrm{Bi}_{2} \mathrm{O}_{3}$ to be $6.8 \mathrm{kcal} / \mathrm{mole}[2]$. This value is listed in tables of thermodynamic data [3, 4]. Levin and McDaniel [5] applying the same Clausius-Clapeyron equation to the $\mathrm{Bi}_{2} \mathrm{O}_{3}-\mathrm{B}_{2} \mathrm{O}_{3}$ system obtained a heat of fusion value of $2.0_{5} \mathrm{kcal} / \mathrm{mole}$. Gattow and Schröder [6] and Gattow and Schütze [7] have used these two values in conjunction with differential thermal analysis (DTA) data to calculate the heat of transition of monoclinic- to cubicbismuth oxide (see table 1). They found that the area of the peak representing the monoclinic to cubic transition was $4.10 \pm 0.11$ times the area of the peak representing the cubic to liquid transformation; and, consequently, the heat of transition should be 4.10 $x$ the heat of fusion.

TABLE 1. Heats of transformations in bismuth oxide

\begin{tabular}{|c|c|c|c|}
\hline \multirow{2}{*}{ Investigator } & \multirow{2}{*}{ Method } & \multicolumn{2}{|c|}{ Heat of transformation } \\
\hline & & $\begin{array}{l}\text { Transition } \\
(\operatorname{mon} \rightarrow c)\end{array}$ & $\begin{array}{l}\text { Fusion } \\
(c \rightarrow \text { liq })\end{array}$ \\
\hline K. K. Kelley (1936) [2] & $\begin{array}{l}\mathrm{Bi}_{2} \mathrm{O}_{3}-\mathrm{PbO} \text { liquidus } \\
\text { [1] }\end{array}$ & kcal/mole & $\begin{array}{r}\mathrm{kcal} / \mathrm{mole} \\
6.8\end{array}$ \\
\hline $\begin{array}{l}\text { Levin and McDaniel (1962) [5] } \\
\text { Gattow and Schröder (1962) [6] } \\
\text { Gattow and Schütze (1964) [7] } \\
\text { Levin and McDaniel (1964) }\end{array}$ & $\begin{array}{l}\mathrm{Bi}_{2} \mathrm{O}_{3}-\mathrm{B}_{2} \mathrm{O}_{3} \text { liquidus } \\
\text { DTA }^{a} \\
\text { DTA }^{b} \\
\text { DTA }^{c}\end{array}$ & $\begin{array}{r}27.9 \pm 1.0 \\
8.4 \pm 0.3 \\
9.9 \pm 0.5\end{array}$ & $3.9 \pm 0.2$ \\
\hline
\end{tabular}

${ }^{a}$ Heat of transformation $=(4.10 \pm 0.11) \times$ heat of fusion $(6.8 \mathrm{kcal} / \mathrm{mole})$.

${ }^{b}$ Heat of transformation $=(4.10 \pm 0.11) \times$ heat of fusion $(2.05 \mathrm{kcal} / \mathrm{mole})$

${ }^{c}$ Using $\mathrm{K}_{2} \mathrm{SO}_{4}$ and $\mathrm{Ag}$ as internal standards.

${ }^{1}$ Figures in brackets indicate the literature references at the end of this paper.
The two reported values for the heat of fusion of $\mathrm{Bi}_{2} \mathrm{O}_{3}$ differ by a factor of about three. The value of $6.8 \mathrm{kcal} / \mathrm{mole}$ obtained from the $\mathrm{Bi}_{2} \mathrm{O}_{3}-\mathrm{PbO}$ diagram is suspect for two reasons: First, a reinvestigation of the $\mathrm{Bi}_{2} \mathrm{O}_{3}-\mathrm{PbO}$ system [8] has shown Belladen's simple liquidus diagram to be incorrect, inasmuch as $\mathrm{PbO}$ exists in solid solution with $\mathrm{Bi}_{2} \mathrm{O}_{3}$ at the liquidus. Second, the sum of the reported entropy of transition and of fusion, $\left(\frac{6800}{1098}+\frac{27900}{1003} / 5\right)$, is about $7 \mathrm{cal} /{ }^{\circ} \mathrm{K} / \mathrm{g}$ atom, an abnormally high value.

Because of the increasing importance of $\mathrm{Bi}_{2} \mathrm{O}_{3}$ in the electronics and ceramics industries, it is desirable to verify the basic thermodynamic data. As equipment for direct calorimetric measurement was not available, differential thermal analysis, using internal standards, was selected as a convenient, independent method for determining heats of transformation.

\section{Equipment}

The differential thermal analysis equipment was built in the laboratory and is of conventional design. The furnace heating element consists of a ceramic core 10 in. long $\times 23 / 8$ in. o.d., wound with 20 gage, 80 percent Pt: 20 percent $R h$, wire. Linear temperature rise with time is accomplished by means of a program controller and a pneumatically activated variable autotransformer. Heating rates of $3 \% \mathrm{~min}$ and $9^{\circ} \% \mathrm{~min}$ are obtained by controlling the percentage of time during which the set point is driven. Using a multipoint recorder, the emfs of the sample thermocouple and of the differential thermocouple are plotted as a function of time. Determinations are made at overall sensitivities of $14 \mu \mathrm{V} / \mathrm{in}$.

To minimize errors that might be caused by poor thermal diffusivity, a special holder assembly is used. 
The two thermocouples $(\mathrm{Pt}-90$ percent $\mathrm{Pt}: 10$ percent $\mathrm{Rh}$ ) from the holder assembly are welded, near the bottom, to $\mathrm{Pt}$ containers. The containers are made from $\mathrm{Pt}$ tubing and measured $16 \mathrm{~mm}$ long $\times 2.6 \mathrm{~mm}$ i.d. $\times 3.0 \mathrm{~mm}$ o.d. The tubes contain a total of 0.2 to $0.4 \mathrm{~g}$ of material, depending on the substances and weight ratios studied. To reduce the effect of air currents in the furnace, the $\mathrm{Pt}$ tubes are covered with thin ceramic thimbles.

\section{Method}

The usual procedure for measuring heats of transformation by DTA depends on calibration of the equipment with a known weight of a standard, e.g., benzoic acid, $\mathrm{AgNO}_{3}, \mathrm{KNO}_{3}[9$, p. 111] and $[10,11]$. The calibration can be expressed in terms of calories per unit of integrated peak area, in the differential temp.-time curve representing the transformation. Assuming approximate constancy of the calibration factor, the unknown heat of transformation for a substance can be determined from the peak area in its differential temp.-time curve.

The method depends on conditions that are seldom closely realized. First, the geometry of the physical arrangement and other operating conditions should be exactly the same for the determination of the unknown as for the calibration with the standard. Second, and even more unlikely, such thermal properties as conductivity, diffusivity, and specific heat should be essentially identical for the two samples.

A method using internal standards avoids the problems inherent in a separate calibration method. Therefore, several high-purity chemicals, with appropriate temperatures and heats of transformations were tried, in a search for internal standards.

Two substances were found satisfactory for calibrants: (1) Finely ground crystalline $\mathrm{K}_{2} \mathrm{SO}_{4}$ with a heat of transition $\left(\alpha^{583} \stackrel{\circ}{\circ} \mathrm{C} \beta\right)$ of $2.14 \mathrm{kcal} / \mathrm{mole}[3,12]$. (2) Fine, precipitated $\mathrm{Ag}$ powder with a heat of fusion $\left(s \stackrel{960.8^{\circ} \mathrm{C}}{\longrightarrow}\right.$ liq. $)$ of $2.61 \mathrm{kcal} / \mathrm{mole}^{2}[13]$. The transformation temperatures in these two substances bracket the transition temp. of $\mathrm{Bi}_{2} \mathrm{O}_{3}$ (monoclinic $\stackrel{7300^{\circ} \mathrm{C}}{\rightarrow}$ cubic) and the fusion temp. of $\mathrm{Bi}_{2} \mathrm{O}_{3}$ (cubic $\stackrel{825}{\rightarrow} \mathrm{C}$ liquid). Two additional substances, $\mathrm{NaCl}$ and $\mathrm{Li}_{2} \mathrm{SO}_{4}$, were found to be unsatisfactory as internal calibration standards.

DTA experiments were carried out for $\mathrm{Bi}_{2} \mathrm{O}_{3}: \mathrm{K}_{2} \mathrm{SO}_{4}$ mixtures in wt. ratios of $3.46: 1,1.72: 1$, and $1.00: 1$; and for $\mathrm{Bi}_{2} \mathrm{O}_{3}: \mathrm{Ag}$ mixtures in wt ratios of $4.32: 1$, $2.16: 1$, and $2.00: 1$. Mixtures were made in $2 \mathrm{~g}$ batches by shaking in a mechanical mixer accurately weighed amounts of dried starting materials. As will be shown below under "Derivation of Equations" the heat of transformation calculations are not based on the actual weights of the two substances in the sample holder but only on the formulated ratios.

Each mixture was given a preliminary heat-cycling treatment by heating the mixture at $12{ }^{\circ} \mathrm{C} / \mathrm{min}$ to about

\footnotetext{
${ }^{2}$ The literature values reported for the heats of transformations in $\mathrm{K}_{2} \mathrm{SO}_{4}$ and $\mathrm{Ag}$ vary over a range of about 10 percent. The values selected here are shown later in this paper (see Internal Consistency) to be self-consistent.
}

$775{ }^{\circ} \mathrm{C}$ (above the transition of $\mathrm{K}_{2} \mathrm{SO}_{4}$ and $\mathrm{Bi}_{2} \mathrm{O}_{3}$ but below the melting point of $\mathrm{Bi}_{2} \mathrm{O}_{3}$ ) and then cooling to room temperature. The preliminary heat treatment was followed by three successive cycles of heating to above the mp of $\mathrm{Bi}_{2} \mathrm{O}_{3}$ in $\mathrm{K}_{2} \mathrm{SO}_{4}$ mixtures and above the $\mathrm{mp}$ of $\mathrm{Ag}$ in $\mathrm{Ag}$ mixtures. The heating and cooling rates for the three cycles were $3 \% \mathrm{~min}, 9^{\circ} \mathrm{min}$, and $3 \% \mathrm{~min}$, respectively. Only the peak areas in heating curves were considered, as previous work, using both DTA and high-temperature x-ray techniques [14], had shown that the stable high-temperature cubic phase is supercooled below the equilibrium transition temperature of $730{ }^{\circ} \mathrm{C}$; and at about $650{ }^{\circ} \mathrm{C}$ a metastable tetragonal and/or body-centered cubic phase is formed, which in turn, transforms back to the stable monoclinic form.

To check on the internal consistency of the method and to evaluate the accuracy, DTA determinations were made with mixtures of the two standards, at the same heating rates and at weight ratios of $\mathrm{K}_{2} \mathrm{SO}_{4}: \mathrm{Ag}$ of $1.36: 1$ and $4.00: 1$.

It should be noted that a number of investigators [9] have used internal standards for quantitative estimation of a phase. Barshad [11] has proposed using "indicators" either mixed with the sample or in separate layers, for direct temperature calibration of a DTA curve. However, the use of internal standards for heat of reaction measurements as herein proposed has not been previously reported, according to the best knowledge of the authors.

An obvious and valid à priori criticism of the internalstandard method is the possibility of obtaining erroneous results if reaction occurs between the bismuth oxide and the standards during the heat-cycling treatments. This possibility was foreseen and was shown to be minimal by a number of observations.

(1) The ratio of the areas under the peaks representing the monoclinic to cubic transition and the cubic to liquid transformation for pure $\mathrm{Bi}_{2} \mathrm{O}_{3}$ could be compared with the corresponding ratio when standards were mixed with the $\mathrm{Bi}_{2} \mathrm{O}_{3}$.

(2) Ratios of corresponding areas for successive heat cycles could be compared with each other, and any discrepancies noted.

(3) At the conclusion of each series of determinations for a given weight ratio, the mixture was examined by x-ray powder diffraction techniques to check for any new phases that might have formed by reaction of the starting materials.

(4) Finally, experimental results could be checked for conformance to theory.

By the criteria listed above, it was possible to evaluate the individual experimental data and to eliminate the few values which were obviously in error. However, even in these instances, the evidence did not indicate chemical reaction of the $\mathrm{Bi}_{2} \mathrm{O}_{3}$, but pointed to physical factors.

\section{Derivation of Equations}

It can be shown that to a close approximation $[9, \mathrm{p}$. 111] the total heat of reaction in a DTA determination 
is given by:

$$
\Delta H=\frac{c K_{s}}{g} \int y d t=\frac{c K_{s}}{g} \cdot A
$$

where, $H=$ heat of transformation per $\mathrm{g}$

$$
c=\text { geometrical shape constant }
$$

$K_{s}=$ thermal conductivity of the sample

$g=$ mass of reactive component in sample

$$
\int y d t=A=\text { peak area for the transformation. }
$$

If two substances, designated by subscripts 1 and 2 , are considered in a mixture, eq (1) may be applied to each substance. Assuming no reaction between the substances, constancy in $c$, and approximate constancy in $K_{s}$ (now the combined thermal conductivity of the mixture), the following expression is readily obtained:

$$
\frac{\Delta H_{1}}{\Delta H_{2}}=\frac{A_{1} g_{2}}{A_{2} g_{1}} .
$$

As $\Delta H_{1}$ and $\Delta H_{2}$ are constants, $g_{2} / g_{1}$ is the weight ratio of the binary mixture, as formulated, and $A_{1} / A_{2}$ is the experimentally measured peak area ratio of the two transformations, the basic equation for an unknown heat of transformation becomes:

$$
\Delta H_{1}=\Delta H_{2}\left(\frac{g_{2}}{g_{1}}\right)\left(\frac{A_{1}}{A_{2}}\right) .
$$

It may be noted that eq (3) is a straight line that passes through the origin and with slope, $m$, equal to $\left(A_{1} / A_{2}\right) /\left(g_{1} / g_{2}\right)$. Thus, over the range that the assumptions made in the derivation hold true, a linear relationship should exist between the formulated weight ratios and the corresponding measured peak area ratios.

If the heat of transformation is desired directly in $\mathrm{kcal} /$ mole rather than on a gram basis, eq (3) may be transformed to:

$$
L_{1}=L_{2}\left(\frac{M_{1}}{M_{2}}\right)\left(\frac{A_{1}}{A_{2}}\right) /\left(\frac{g_{1}}{g_{2}}\right)
$$

where, $L_{1}$ and $L_{2}$ are the heats of transformation of substances 1 and 2 , respectively, in $\mathrm{kcal} / \mathrm{mole}$, and

$M_{1}$ and $M_{2}$ are the corresponding molecular weights.

Applying eq (4) to the specific case of $\mathrm{Bi}_{2} \mathrm{O}_{3}: \mathrm{K}_{2} \mathrm{SO}_{4}$ mixtures:

$$
L_{\mathrm{Bi}_{2} \mathrm{O}_{3}}=2.14\left(\frac{465.96}{174.27}\right)\left(\frac{A_{\mathrm{Bi}_{2} \mathrm{O}_{3}}}{A_{\mathrm{K}_{2} \mathrm{SO}_{4}}}\right) /\left(\frac{g_{\mathrm{Bi}_{2} \mathrm{O}_{3}}}{g_{\mathrm{K}_{2} \mathrm{SO}_{4}}}\right)=5.722 m_{1}
$$

where, $L_{\mathrm{Bi}_{2} \mathrm{O}_{3}}$ refers to the heat of transformation (transition or fusion), in $\mathrm{kcal} /$ mole;

$2.14=$ the heat of transition of $\mathrm{K}_{2} \mathrm{SO}_{4}$, from the $\alpha$ to $\beta$ form, in $\mathrm{kcal} / \mathrm{mole}$;

$465.96 / 174.27=$ the molecular weight ratio of $\mathrm{Bi}_{2} \mathrm{O}_{3}$ to $\mathrm{K}_{2} \mathrm{SO}_{4}$; and

$m_{1}=$ the slope of the line obtained by plot ting as ordinate the ratio of the peak areas representing the particular transformation of $\mathrm{Bi}_{2} \mathrm{O}_{3}$ to the transition of $\mathrm{K}_{2} \mathrm{SO}_{4}\left(A_{\mathrm{Bi}_{2} \mathrm{O}_{3}} / A_{\mathrm{K}_{2} \mathrm{SO}_{4}}\right)$ and plotting as abscissa the corresponding weight ratio of $\mathrm{Bi}_{2} \mathrm{O}_{3}$ to $\mathrm{K}_{2} \mathrm{SO}_{4}$ $\left(g_{\mathrm{Bi}_{2} \mathrm{O}_{3}} / g_{\mathrm{K}_{2} \mathrm{SO}_{4}}\right)$.

Applying eq (4) to the case of $\mathrm{Bi}_{2} \mathrm{O}_{3}$ : $\mathrm{Ag}$ mixtures:

$$
L_{\mathrm{Bi}_{2} \mathrm{O}_{3}}=2.61\left(\frac{465.96}{107.87}\right)\left(\frac{A_{\mathrm{Bi}_{2} \mathrm{O}_{3}}}{A_{\mathrm{Ag}}}\right) /\left(\frac{g_{\mathrm{Bi}_{2} \mathrm{O}_{3}}}{g_{\mathrm{Ag}}}\right)=11.274 m_{2}
$$

where, $2.61=$ the heat of fusion of $\mathrm{Ag}$, in $\mathrm{kcal} / \mathrm{mole}$, $465.96 / 107.87=$ the molecular weight ratio of $\mathrm{Bi}_{2} \mathrm{O}_{3}$ to $\mathrm{K}_{2} \mathrm{SO}_{4}$, and $m_{2}$ is the slope of the line obtained by plotting $\frac{A_{\mathrm{Bi}_{2} \mathrm{O}_{3}}}{A_{\mathrm{Ag}}}$ as ordinate versus $\frac{g_{\mathrm{Bi}_{2} \mathrm{O}_{3}}}{g_{\mathrm{Ag}}}$ as abscissa.

Applying eq (4) to the case of mixtures of the two standards, $\mathrm{K}_{2} \mathrm{SO}_{4}$ and $\mathrm{Ag}$ :

$$
L_{\mathrm{K}_{2} \mathrm{SO}_{4}}=2.61\left(\frac{174.27}{107.87}\right)\left(\frac{A_{\mathrm{K}_{2} \mathrm{SO}_{4}}}{A_{\mathrm{Ag}}}\right) /\left(\frac{g_{\mathrm{K}_{2} \mathrm{SO}_{4}}}{g_{\mathrm{Ag}}}\right)=4.217 m_{3}
$$

where, $L_{\mathrm{K}_{2} \mathrm{SO}_{4}}=$ the heat of transition of $\mathrm{K}_{2} \mathrm{SO}_{4}$, in $\mathrm{kcal} / \mathrm{mole}$;

$2.61=$ the heat of fusion of $\mathrm{Ag}$, in $\mathrm{kcal} /$ mole $174.27 / 107.87=$ the molecular weight ratio of $\mathrm{K}_{2} \mathrm{SO}_{4}$ to $\mathrm{Ag}$; and

$m_{3}=$ the slope of the line obtained by plotting $\frac{A_{\mathrm{K}_{2} \mathrm{SO}_{4}}}{A_{\mathrm{Ag}}}$ as ordinate versus $\frac{g_{\mathrm{K}_{2} \mathrm{SO}_{4}}}{g_{\mathrm{Ag}}}$ as abscissa.

Inasmuch as DTA determinations were made in binary combinations of the three substances, $\mathrm{Bi}_{2} \mathrm{O}_{3}$, $\mathrm{K}_{2} \mathrm{SO}_{4}$, and $\mathrm{Ag}$, it is possible to evaluate the internal consistency of the method. From eqs (5), (6), and (7), where $m_{1}, m_{2}$, and $m_{3}$ are given in terms of the specific ratios, it follows that any one ratio can be determined independently from the other two, for example:

$$
\frac{\frac{A_{\mathrm{Bi}_{2} \mathrm{O}_{3}}}{A_{\mathrm{Ag}}} \cdot \frac{g_{\mathrm{Ag}}}{g_{\mathrm{Bi}_{2} \mathrm{O}_{3}}}}{\frac{A_{\mathrm{Bi}_{2} \mathrm{O}_{3}}}{A_{\mathrm{K}_{2} \mathrm{SO}_{4}}} \cdot \frac{g_{\mathrm{K}_{2} \mathrm{SO}_{4}}}{g_{\mathrm{Bi}_{2} \mathrm{O}_{3}}}} \frac{A_{\mathrm{Ag}}}{A_{\mathrm{Ag}}} \cdot \frac{g_{\mathrm{Ag}}}{g_{\mathrm{K}_{2} \mathrm{SO}_{4}}}
$$




\section{Results and Discussion}

\subsection{General}

Figure 1 shows a reproduction of the DTA curve for one of the $\mathrm{Bi}_{2} \mathrm{O}_{3}: \mathrm{K}_{2} \mathrm{SO}_{4}$ mixtures. The various transformations within the phases are labeled. Peak areas were obtained by tracing the curve on millimeter ruled graph paper and averaging several counts. The modification of the sample holder in conjunction with the amplification of the equipment was found to be sensitive to heat of reaction effects. In a $1: 1$ mixture of $\mathrm{Bi}_{2} \mathrm{O}_{3}: \mathrm{K}_{2} \mathrm{SO}_{4}$, for example, $0.1192 \mathrm{~g} \mathrm{~K}_{2} \mathrm{SO}_{4}$ absorbed a calculated 1.4635 calories of heat at the transition and produced an area under the peak of $208 \mathrm{~mm}^{2}$, or about $0.007 \mathrm{cal} / \mathrm{mm}^{2}$. No corrections were applied to the area data for change in thermocouple (Pt-90 percent $\mathrm{Pt}: 10$ percent $\mathrm{Rh}$ ) sensitivity with temperature. Attempted corrections did not improve the results; furthermore, the use of two standards whose transformation temperatures bracketed those of $\mathrm{Bi}_{2} \mathrm{O}_{3}$ provided automatic compensation.

The experimentally determined transformation ratios for pure $\mathrm{Bi}_{2} \mathrm{O}_{3}$ and the binary mixtures between $\mathrm{Bi}_{2} \mathrm{O}_{3}, \mathrm{~K}_{2} \mathrm{SO}_{4}$, and $\mathrm{Ag}$ are given in table 2. Transformation ratios as a function of weight ratios are plotted in figures 2, 3, and 4. Slopes of the lines and standard deviations of the slopes were determined by the method of least squares for lines passing through the origin. If the assumptions used previously in deriving the linear relationships hold, then the origin constitutes a valid fixed point, for obviously as $g_{\mathrm{Bi}_{2} \mathrm{O}_{3}}$ in the mixture approaches 0 , so does $A_{\mathrm{Bi}_{2} \mathrm{O}_{3}}$ and consequently so do the ratios $g_{\mathrm{Bi}_{2} \mathrm{O}_{3}} / g_{\mathrm{K}_{2} \mathrm{SO}_{4}}$ and $A_{\mathrm{Bi}_{2} \mathrm{O}_{3}} / A_{\mathrm{K}_{2} \mathrm{SO}_{4}}$.

Examining the transformation ratios (table 2) as a function of the $3 \% \mathrm{~min}$ and $9^{\circ} / \mathrm{min}$ heating rates or as a function of the heating cycle (1st, $2 \mathrm{~d}$, or $3 \mathrm{~d}$ ), no overall trend of statistical significance can be discerned. The average ratios of the $\mathrm{Bi}_{2} \mathrm{O}_{3}$ transformations $(\mathrm{M} \rightarrow c)$ $c \rightarrow 1$ ) of 2.54 and 2.52 for the $\mathrm{Bi}_{2} \mathrm{O}_{3}: \mathrm{K}_{2} \mathrm{SO}_{4}$ mixtures and of 2.53 for the $\mathrm{Bi}_{2} \mathrm{O}_{3}: \mathrm{Ag}$ mixture $(4.32: 1)$ are in good agreement with each other and with that for pure $\mathrm{Bi}_{2} \mathrm{O}_{3}, 2.46$. However, the ratios of 3.20 and 2.80 for the $\mathrm{Bi}_{2} \mathrm{O}_{3}$ transformations in the $\mathrm{Ag}$ mixtures $(2.16: 1$ and $2.00: 1$ ) appear high. The heat of fusion of $\mathrm{Bi}_{2} \mathrm{O}_{3}$ is 2/5 that of the heat of transition, and the shape of the fusion peak tends to be low and flat (see fig. 1). Therefore, as the amount of $\mathrm{Bi}_{2} \mathrm{O}_{3}$ decreases in the mixture, the peak area for fusion becomes less defined and broader tending to give a low area count.

It may be noted in figure 2 for the $\mathrm{Bi}_{2} \mathrm{O}_{3}: \mathrm{K}_{2} \mathrm{SO}_{4}$ mixtures that the curves deviate from linearity above a 2:1 wt ratio of $\mathrm{Bi}_{2} \mathrm{O}_{3}: \mathrm{K}_{2} \mathrm{SO}_{4}$. This deviation is not due to any significant reaction between $\mathrm{Bi}_{2} \mathrm{O}_{3}$ and $\mathrm{K}_{2} \mathrm{SO}_{4}$ but to poor thermal properties of the $\mathrm{Bi}_{2} \mathrm{O}_{3}$ mixture. For the mixtures containing Ag, which is a good thermal conductor and which has been used to improve thermal transfer $[9,15]$, linearity extends beyond the 4:1 ratio of substance to $\mathrm{Ag}$ (fig. 3 and 4). Therefore, the area ratios for the 3.46 to 1 wt ratio of $\mathrm{Bi}_{2} \mathrm{O}_{3}$ to $\mathrm{K}_{2} \mathrm{SO}_{4}$ were not used in computing the slopes.

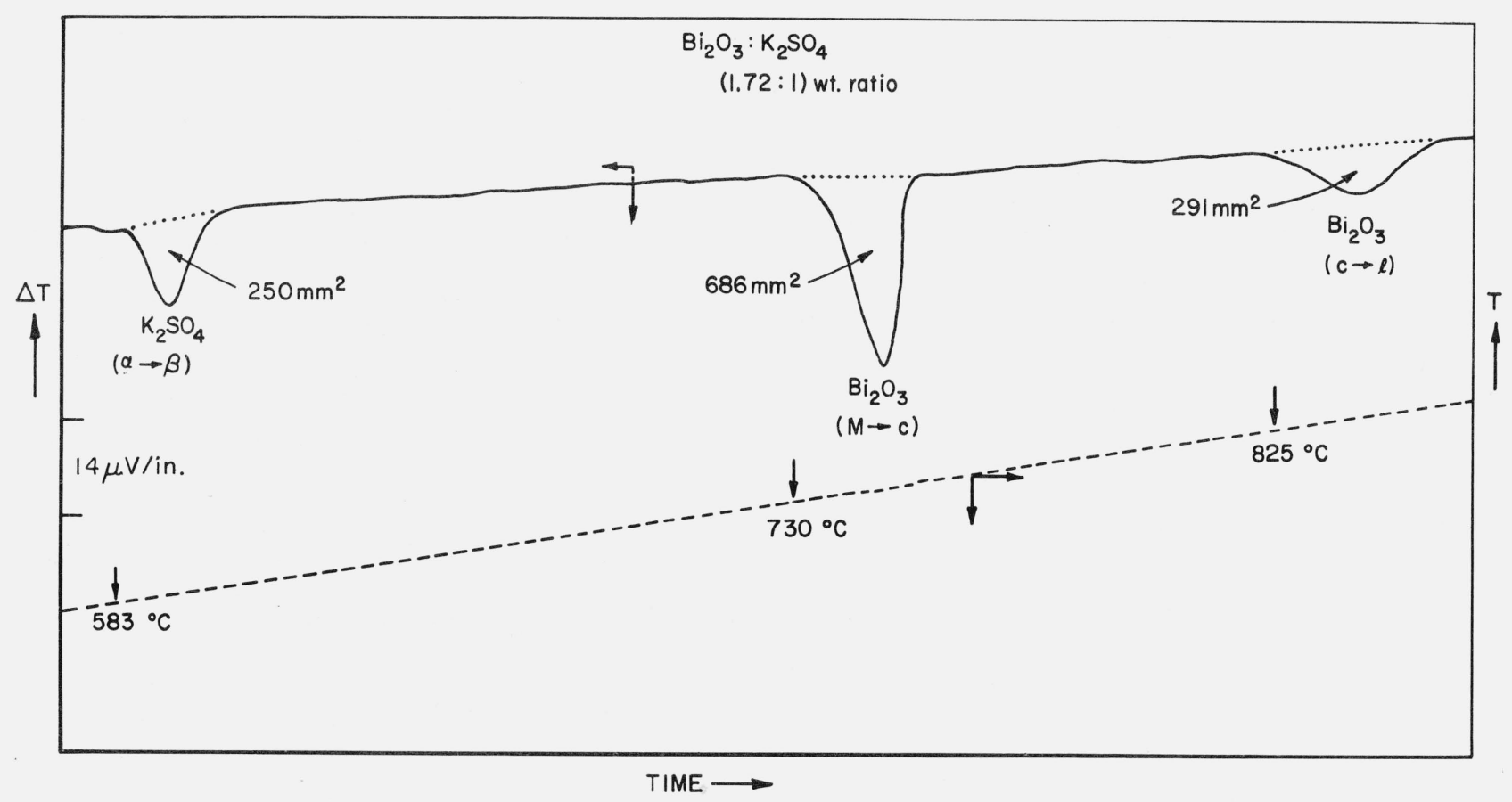

FIGURE 1. Differential thermal analysis curve for third cycle of heat treatment of $\mathrm{Bi}_{2} \mathrm{O}_{3}: \mathrm{K}_{2} \mathrm{SO}_{4}$ mixtures of weight ratio $1.72: 1$.

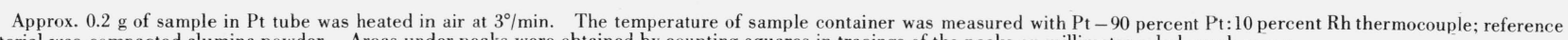
material was compacted alumina powder. Areas under peaks were obtained by counting squares in tracings of the peaks on millimeter ruled graph paper. $\alpha \rightarrow \beta=$ transition of $\mathrm{K}_{2} \mathrm{SO}_{4}$

$M \rightarrow c=$ monoclinic to cubic transition of $\mathrm{Bi}_{2} \mathrm{O}_{3}$

$c \rightarrow l=$ fusion of cubic $\mathrm{Bi}_{2} \mathrm{O}_{3}$. 
TABLE 2. Ratio of peak areas between transformations in $\mathrm{Bi}_{2} \mathrm{O}_{3}$ and in binary mixtures of $\mathrm{Bi}_{2} \mathrm{O}_{3}, \mathrm{~K}_{2} \mathrm{SO}_{4}$, and $\mathrm{Ag}$, as a function of heating rates and weight ratios*

\begin{tabular}{c|c|c|c|c|l}
\hline \hline & \multirow{2}{*}{$\begin{array}{c}\text { Transformation } \\
\text { ratios }^{a} \\
A_{1} / A_{2}\end{array}$} & \multicolumn{4}{|c}{ Ratio of peak areas at heating rates: } \\
\cline { 3 - 6 } wt. ration & & $3^{\circ} / \mathrm{min}$ & $9^{\circ} / \mathrm{min}$ & $3^{\circ} / \mathrm{min}$ & Average \\
& & &
\end{tabular}

\begin{tabular}{|c|c|c|c|c|c|}
\hline \multicolumn{6}{|c|}{$\mathrm{Bi}_{2} \mathrm{O}_{3}$ (pure) } \\
\hline & $\frac{M \rightarrow c}{c \rightarrow l}$ & 2.47 & 2.57 & 2.33 & 2.46 \\
\hline \multicolumn{6}{|c|}{$\mathrm{Bi}_{2} \mathrm{O}_{3}: \mathrm{K}_{2} \mathrm{SO}_{4}$ mixtures } \\
\hline \multirow{3}{*}{$\frac{\frac{77.6 \mathrm{Bi}_{2} \mathrm{O}_{3}}{22.4 \mathrm{~K}_{2} \mathrm{SO}_{4}}}{(3.46: 1)}$} & $\frac{M \rightarrow c}{c \rightarrow l}$ & 2.86 & 2.18 & 2.58 & $2.54^{\prime}$ \\
\hline & $\frac{M \rightarrow c}{\alpha \rightarrow \beta}$ & 4.67 & 4.87 & 4.57 & 4.70 \\
\hline & $\frac{c \rightarrow l}{\alpha \rightarrow \beta}$ & 1.63 & 2.23 & 1.92 & 1.93 \\
\hline \multirow{3}{*}{ 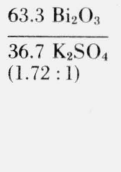 } & $M \rightarrow c$ & & & & \\
\hline & $\begin{array}{l}\overline{c \rightarrow l} \\
M \rightarrow c\end{array}$ & 2.51 & 2.70 & 2.36 & 2.52 \\
\hline & $\begin{array}{l}\alpha \rightarrow \beta \\
c \rightarrow l \\
\alpha \rightarrow \beta\end{array}$ & 1.21 & 1.09 & 1.16 & 1.15 \\
\hline $\begin{array}{l}\frac{50.0 \mathrm{Bi}_{2} \mathrm{O}_{3}}{50.0 \mathrm{~K}_{2} \mathrm{SO}_{4}} \\
(1.00: 1)\end{array}$ & $\frac{M \rightarrow c^{b}}{\alpha \rightarrow \beta}$ & 1.61 & 1.61 & 1.62 & 1.61 \\
\hline
\end{tabular}

$\mathrm{Bi}_{2} \mathrm{O}_{3}: \mathrm{Ag}$ mixtures

\begin{tabular}{|c|c|c|c|c|c|}
\hline$\frac{81.2 \mathrm{Bi}_{2} \mathrm{O}_{3}}{18.8 \mathrm{Ag}}$ & $\frac{M \rightarrow c}{c \rightarrow l}$ & 2.56 & 2.52 & 2.51 & 2.53 \\
\hline$(4.32: 1)$ & $\frac{M \rightarrow c}{s \rightarrow l}$ & 3.91 & 3.82 & 3.96 & 3.90 \\
\hline & $\frac{c \rightarrow l}{s \rightarrow l}$ & 1.52 & 1.51 & 1.58 & 1.54 \\
\hline$\frac{68.35 \mathrm{Bi}_{2} \mathrm{O}_{3}}{31.65 \mathrm{Ag}}$ & $\frac{M \rightarrow c}{c \rightarrow l}$ & $3.10^{c,}$ & $3.29^{\mathrm{d}}$ & & $3.20^{\circ}$ \\
\hline$(2.16: 1)$ & $\frac{M \rightarrow c}{s \rightarrow l}$ & $2.14^{c}$ & 1.68 & & 1.91 \\
\hline & $\frac{c \rightarrow l}{s \rightarrow l}$ & $0.69^{c}$ & 0.51 & & 0.60 \\
\hline $66.7 \mathrm{Bi}_{2} \mathrm{O}_{3}$ & $\underline{M \rightarrow c}$ & & 2.80 & & $2.80^{d}$ \\
\hline $\begin{array}{l}33.3 \mathrm{Ag} \\
(2.00: 1)\end{array}$ & $\begin{array}{c}c \rightarrow l \\
M \rightarrow c \\
\frac{M}{s \rightarrow l}\end{array}$ & 1.99 & 1.72 & & 1.86 \\
\hline & $\frac{c \rightarrow l}{s \rightarrow l}$ & & 0.61 & & 0.61 \\
\hline
\end{tabular}

$\mathrm{K}_{2} \mathrm{SO}_{4}: \mathrm{Ag}$ mixtures

\begin{tabular}{l|l|l|l|l|l}
\hline $57.7 \mathrm{~K}_{2} \mathrm{SO}_{4}$ & $\frac{\alpha \rightarrow \beta}{s \rightarrow l}$ & 0.637 & 0.638 & 0.604 & 0.626 \\
\hline $42.3 \mathrm{Ag}$ & $\frac{\alpha \rightarrow \beta}{s \rightarrow 36: 1)}$ & 2.27 & 2.16 & 2.07 & 2.17 \\
$\frac{80.0 \mathrm{~K}_{2} \mathrm{SO}_{4}}{20.0 \mathrm{Ag}}$ & & & & & \\
\hline$(4.00: 1)$ & & & \\
\hline
\end{tabular}

*Sample weights varied from 0.2 to $0.4 \mathrm{~g}$, depending on the particular mixtures. Samples were contained in $\mathrm{Pt}$ tubes and heated in air. Sensitivity on the differential temperature scale was $14 \mu \mathrm{v} / \mathrm{in}$.

a Refers to ratio of peak areas between the indicated transformations:

$M \rightarrow c$, monoclinic to cubic transition of $\mathrm{Bi}_{2} \mathrm{O}_{3}$ phase at $730^{\circ} \mathrm{C}$

$M \rightarrow c$, monoclinic to cubic transition of $\mathrm{Bi}_{2} \mathrm{O}_{3}$ phase at $730^{\circ} \mathrm{C}$

$c \rightarrow l$, cubic to liquid transformation of $\mathrm{Bi}_{2} \mathrm{O}_{3}$ phase at 825
$\alpha \rightarrow \beta$, low to high transition of $\mathrm{K}_{2} \mathrm{SO}_{4}$ phase at $583{ }^{\circ} \mathrm{C}$

$\alpha \rightarrow \beta$, low to high transition of $\mathrm{K}_{2} \mathrm{SO}_{4}$ phase at $583{ }^{\circ} \mathrm{C}$
$s \rightarrow l$, solid to liquid transformation of $\mathrm{Ag}$ phase at $960.8{ }^{\circ} \mathrm{C}$

${ }^{\mathrm{b}}$ No values for $\frac{M \rightarrow c}{c \rightarrow l}$ and $\frac{c \rightarrow l}{\alpha \rightarrow \beta}$ ratios as $c \rightarrow l$ transformation of $\mathrm{Bi}_{2} \mathrm{O}_{3}$ is not well defined.

c $12 \%$ min heating rate

d Area for $c \rightarrow l$ transformation of $\mathrm{Bi}_{2} \mathrm{O}_{3}$ appears low.

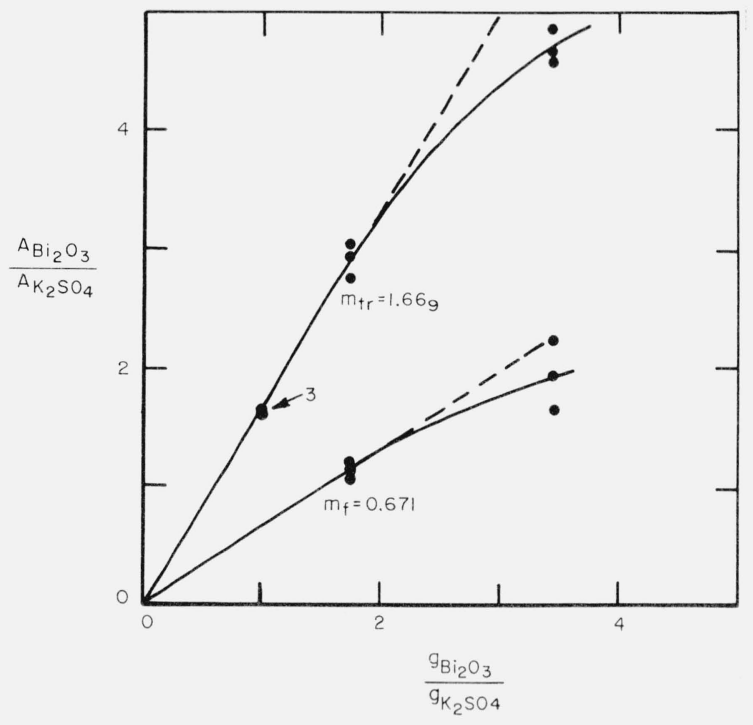

FIGURE 2. Peak area ratios versus weight ratios for mixtures of $\mathrm{Bi}_{2} \mathrm{O}_{3}$ and $\mathrm{K}_{2} \mathrm{SO}_{4}$.

$g_{\mathrm{Bi}_{2} \mathrm{O}_{3}} / g_{\mathrm{K}_{2} \mathrm{SO}_{4}}$ refers to the weight ratio. $A_{\mathrm{Bi}_{2} \mathrm{O}_{3}} / A_{\mathrm{K}_{2} \mathrm{SO}_{4}}$ for slope of line $m_{\mathrm{tr}}$ refers to area under transition of $\mathrm{Bi}_{2} \mathrm{O}_{3} \div$ area under transition of $\mathrm{K}_{2} \mathrm{SO}_{4}$. $A_{\mathrm{Bi}_{2} \mathrm{O}_{3}} / A_{\mathrm{K}_{2} \mathrm{SO}_{4}}$ for slope of line $m_{f}$ refers to area under fusion of $\mathrm{Bi}_{2} \mathrm{O}_{3} \div$ area under transition of $\mathrm{K}_{2} \mathrm{SO}_{4}$. Slopes calculated by method of least squares.

$L_{\mathrm{Bi}_{2} \mathrm{O}_{3}}=5.722 m_{1}$ (see eq (5), in text).

$L_{\mathrm{tr}} \mathrm{Bi}_{2} \mathrm{O}_{3}=5.722 \times 1.66_{9}=9.5 \mathrm{kcal} / \mathrm{mole}$. S. D. $m_{\mathrm{tr}}=0.031$

$L_{f} \mathrm{Bi}_{2} \mathrm{O}_{3}=5.722 \times 0.671=3.8_{4} \mathrm{kcal} /$ mole. S.D. $m_{f}=0.020$

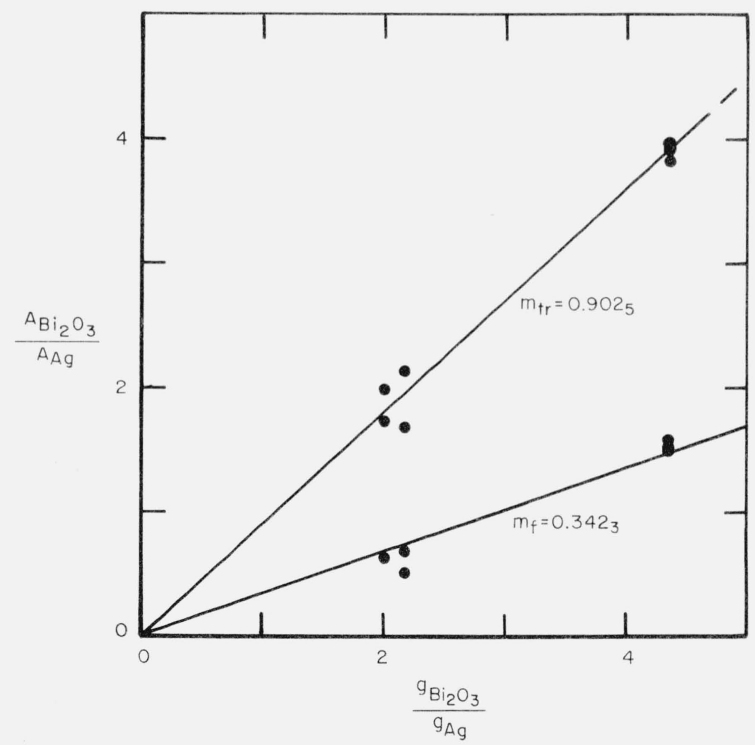

FIGURE 3. Peak area ratios versus weight ratios for mixtures of $\mathrm{Bi}_{2} \mathrm{O}_{3}$ and $\mathrm{Ag}$.

$g_{\mathrm{Bi}_{2} \mathrm{O}_{3}} / \mathrm{g}_{\mathrm{Ag}}$ refers to the weight ratio. $A_{\mathrm{Bi}_{2} \mathrm{O}_{3}} / A_{\mathrm{Ag}}$ for slope of line $m_{\mathrm{tr}}$ refers to area under ransition of $\mathrm{Bi}_{2} \mathrm{O}_{3} \div$ area under fusion of $\mathrm{Ag}$. $\quad A_{\mathrm{Bi}} \mathrm{O}_{3} / A_{\mathrm{Ag}}$ for slope of line $m_{\mathrm{r}}$ refers to area transition of $\mathrm{Bi}_{2} \mathrm{O}_{3} \div$ area under fusion of $\mathrm{Ag}$. $A_{\mathrm{Bi}} \mathrm{O}_{3} / A_{\mathrm{Ag}}$ for slope of line $m_{\mathrm{f}}$ refers to area
under fusion of $\mathrm{Bi}_{2} \mathrm{O}_{3} \div$ area under fusion of $\mathrm{Ag}$. Slopes calculated by method of least

$L_{\mathrm{Bi}_{2} \mathrm{O}_{3}}=11.274 m_{2}$ (see eq $(6)$, in text).

$L_{\mathrm{tr}} \mathrm{Bi}_{2} \mathrm{O}_{3}=11.274 \times 0.902_{5}=10.1_{7} \mathrm{kcal} / \mathrm{mole}$. S.D. $m_{\mathrm{tr}}=0.019$.

$L_{\mathrm{f}} \mathrm{Bi}_{2} \mathrm{O}_{3}=11.27 \times 0.342_{3}=3.8_{6} \mathrm{kcal} / \mathrm{molel}$. S.D. $m_{f}=0.015$ 


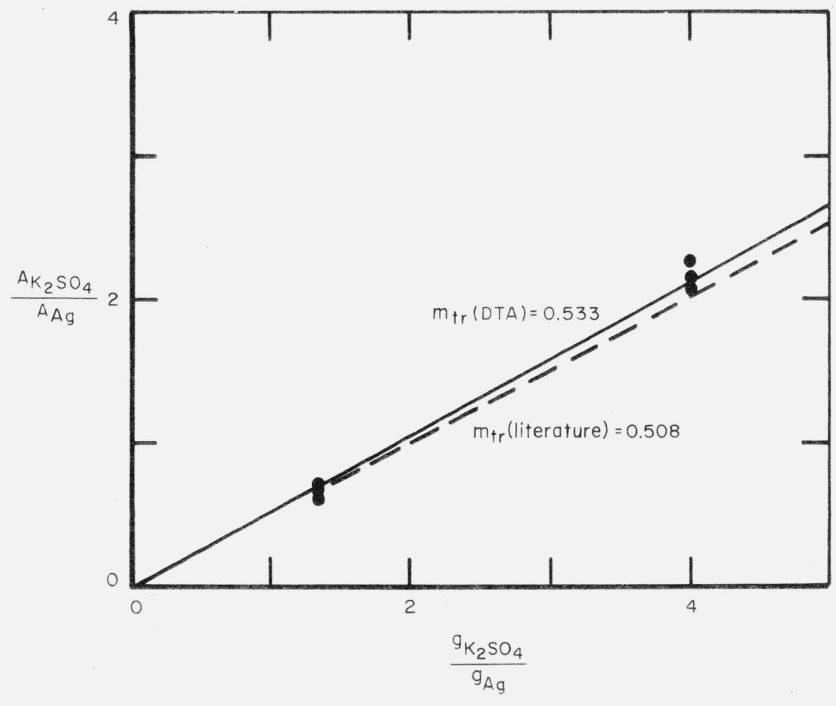

Figure 4. Peak area ratios versus weight ratios for mixtures of $\mathrm{K}_{2} \mathrm{SO}_{4}$ and $\mathrm{Ag}$.

$g_{\mathrm{K} 2} \mathrm{SO}_{4} / g_{\mathrm{Ag}}$ refers to the weight ratio. $\quad A_{\mathrm{K}_{2} \mathrm{SO}_{4}} / A_{\mathrm{Ag}}$ for slope of line $m_{\mathrm{tr}}$ (DTA) refers to the area under the transition of $\mathrm{K}_{2} \mathrm{SO}_{4} \div$ area under the fusion of Ag. Slope for solid line calcu. lated by method of least squares; slope for dashed line calculated from literature values. $L_{\mathrm{K}_{2} \mathrm{SO}_{4}}=4.217 m_{3}$ (see eq (7), in text).

$L_{\mathrm{tr}} \mathrm{K}_{2} \mathrm{SO}_{4}=4.217 \times 0.533=2.2 . \mathrm{kcal} / \mathrm{mole} . \mathrm{S} . \mathrm{D}, m_{\mathrm{tr}}=0.014$

$L_{\mathrm{tr}} \mathrm{K}_{2} \mathrm{SO}_{4}$, from literature $[3,12]=2.14 \mathrm{kcal} / \mathrm{mole}$

\subsection{Heats of Transformations}

By application of eq (5) to the slopes in figure 2 :

$$
\begin{aligned}
L_{\mathrm{tr}} \mathrm{Bi}_{2} \mathrm{O}_{3}(M \rightarrow c) & =5.722 \times 1.669=9.5_{5} \mathrm{kcal} / \mathrm{mole} \\
\text { S.D. } m_{\mathrm{tr}} & =0.031(0.30 \mathrm{kcal} / \mathrm{mole}) \\
L_{f} \mathrm{Bi}_{2} \mathrm{O}_{3}(c \rightarrow l) & =5.722 \times 0.671=3.8_{4} \mathrm{kcal} / \mathrm{mole} \\
\text { S.D. } m_{f} & =0.020(0.08 \mathrm{kcal} / \mathrm{mole})
\end{aligned}
$$

Similarly, by application of eq (6) to the slopes for the $\mathrm{Bi}_{2} \mathrm{O}_{3}$ : Ag mixtures (fig. 3):

$$
\begin{aligned}
L_{\mathrm{tr}} \mathrm{Bi}_{2} \mathrm{O}_{3}(M \rightarrow c) & =11.274 \times 0.9025=10.1_{7} \mathrm{kcal} / \mathrm{mole} \\
\text { S.D. } m_{\mathrm{tr}} & =0.019(0.19 \mathrm{kcal} / \mathrm{mole}) \\
L_{f} \mathrm{Bi}_{2} \mathrm{O}_{3}(c \rightarrow l) & =11.274 \times 0.3423=3.8_{6} \mathrm{kcal} / \mathrm{mole} \\
\text { S.D. } m_{f} & =0.015(0.06 \mathrm{kcal} / \mathrm{mole}) .
\end{aligned}
$$

The standard deviations of the slopes for the $\mathrm{Bi}_{2} \mathrm{O}_{3}: \mathrm{Ag}$ mixtures are somewhat lower than for the $\mathrm{Bi}_{2} \mathrm{O}_{3}: \mathrm{K}_{2} \mathrm{SO}_{4}$ mixtures because of the additional data, for the high weight ratio, that could be used in the calculations. Certainly, the difference in the heat of fusion of $\mathrm{Bi}_{2} \mathrm{O}_{3}$ obtained from the two standards is not statistically significant. The difference in values for the heat of transition is of questionable significance.

\subsection{Accuracy}

The linear relationship between area ratios and weight ratios for mixtures of the two standards can be seen in figure 4 . The experimentally determined slope $(0.533)$ is 4.7 percent greater than the theoretical slope (0.508) derived from the literature values. The difference between slopes is about twice the standard deviation of the experimentally determined slope. The agreement is good considering that the binary mixture of standards presents the most extreme in physical conditions of the three binary mixtures. In the $\mathrm{K}_{2} \mathrm{SO}_{4}: \mathrm{Ag}$ mixtures, the area of the solid-solid transition of $\mathrm{K}_{2} \mathrm{SO}_{4}$ at $583{ }^{\circ} \mathrm{C}$ is compared to the area of the solid-liquid transformation of $\mathrm{Ag}$ at $960.8^{\circ} \mathrm{C}$.

Substituting in eq (7) the slope of the transformation ratio shown in figure $4(0.533)$ gives a value of 2.25 $\mathrm{kcal} / \mathrm{mole}$ for the heat of transition of $\mathrm{K}_{2} \mathrm{SO}_{4}$, compared to 2.14 , the literature value. The agreement between these two values, as well as for the slopes, tends to substantiate the standard values used in the calculations, namely, $2.61 \mathrm{kcal} /$ mole for $L_{f}$ of $\mathrm{Ag}$ and 2.14 $\mathrm{kcal} / \mathrm{mole}$ for $L_{\mathrm{tr}}$ of $\mathrm{K}_{2} \mathrm{SO}_{4}$. Attempts to correct for the change in thermocouple sensitivity with temperature or the use of other literature values for the heats of transformation of the standards has a detrimental effect on the agreement.

\subsection{Internal Consistency}

As shown in the development of eqs (8) and (9), it is possible to check the internal consistency of the results through a calculation which does not involve any heat of transformation values. From eqs (8) and (9):

$$
\frac{m_{2}}{m_{1}}=m_{3}=\frac{A_{\mathrm{K}_{2} \mathrm{SO}_{4}}}{A_{\mathrm{Ag}}} \cdot \frac{g_{\mathrm{Ag}}}{g_{\mathrm{K}_{2} \mathrm{SO}_{4}}} .
$$

Substituting the values for the slopes $m_{1}, m_{2}$, and $m_{3}$, as given in figures 2,3 , and 4 , respectively: For transition data, $\frac{0.902_{5}}{1.66_{9}}=0.541$ (calc.) versus 0.533 (expt.). For fusion data, $\frac{0.342_{3}}{0.67_{1}}=0.510$ (calc.) versus 0.533 (expt.).

The internal consistency calculations give deviations between the experimentally determined slope, $m_{3}$, and the calculated one, $m_{2} / m_{1}$, of +1.5 percent, for the transition data and -4 percent for the fusion data. The average of the two calculated slopes agrees to better than 1.5 percent with the experimentally determined one.

\subsection{Conclusion}

Consideration of the three criteria, namely, standard deviation of the slopes, internal consistency, and accuracy, as determined with the binary mixtures of standards, indicate an overall uncertainty of about 5 percent. 
Averaging the results for the heats of transformation of $\mathrm{Bi}_{2} \mathrm{O}_{3}$ obtained from the mixtures with $\mathrm{K}_{2} \mathrm{SO}_{4}$ and Ag, yields:

$$
\begin{gathered}
L_{\mathrm{tr}} \mathrm{Bi}_{2} \mathrm{O}_{3}(M \rightarrow c)=9.9 \pm 0.5 \mathrm{kcal} / \mathrm{mole} \\
L_{f} \mathrm{Bi}_{2} \mathrm{O}_{3}(c \rightarrow l)=3.9 \pm 0.2 \mathrm{kcal} / \mathrm{mole}
\end{gathered}
$$

The sum of the entropy of transition and of fusion equals $\left(\frac{9900}{1003}+\frac{3900}{1098}\right) / 5=2.7 \mathrm{cal} /{ }^{\circ} \mathrm{K} / \mathrm{g}$ atom, a reasonable value [3].

\section{Summary}

To avoid problems inherent in a separate heat of reaction calibration of DTA equipment, a technique was developed which makes use of internal standards.

Binary mixtures of $\mathrm{Bi}_{2} \mathrm{O}_{3}$ and two standards, $\mathrm{K}_{2} \mathrm{SO}_{4}$ and $\mathrm{Ag}$, were formulated in three weight ratios and subjected to three cyclic heat treatments, in the DTA equipment. Small amounts of mixtures, 0.2 to $0.4 \mathrm{~g}$ in total weight, were heated in platinum tubes which were isolated from the tubes containing the reference material, $\mathrm{Al}_{2} \mathrm{O}_{3}$. Thermocouples, Pt-90 percent $\mathrm{Pt}: 10$ percent Rh, of fine wire were welded to the outside of the tubes. The modification of the sample holder and overall sensitivity of the equipment was found to respond to heat effects equivalent to $0.007 \mathrm{cal}$ per $\mathrm{mm}^{2}$ of the area under the peak.

A number of criteria were employed to check on possible reaction between $\mathrm{Bi}_{2} \mathrm{O}_{3}$ and the standards and to eliminate erroneous date. These criteria were as follows: Comparison of corresponding transformation ratios in successive heat cycles; comparison of the transformation ratio $(M \rightarrow c / c \rightarrow l)$ in the $\mathrm{Bi}_{2} \mathrm{O}_{3}$ phase of mixtures with that in pure $\mathrm{Bi}_{2} \mathrm{O}_{3}$; x-ray powder analysis of mixtures at the completion of a determination; and, finally, observing the adherence of the data to linearity as prescribed by theory.

Except for the high weight ratio of $\mathrm{Bi}_{2} \mathrm{O}_{3}$ to $\mathrm{K}_{2} \mathrm{SO}_{4}$ in the 3.46:1 mixture, plots of ratios of transformation areas versus corresponding weight ratios were linear and passed through the origin. The presence of $\mathrm{Ag}$ in the $\mathrm{Bi}_{2} \mathrm{O}_{3}: \mathrm{Ag}$ and the $\mathrm{K}_{2} \mathrm{SO}_{4}: \mathrm{Ag}$ mixtures contributed to thermal transfer, and linearity was observed for all the weight ratios.

The data were analyzed according to (1) standard deviation of the slopes, (2) internal consistency, which is independent of the heat of transformation of the standards, and (3) agreement between calculated and selected literature value when one standard is mixed with the other. The heat of transition of $\mathrm{Bi}_{2} \mathrm{O}_{3}$ was found to be $9.9 \pm 0.5 \mathrm{kcal} / \mathrm{mole}$ and the heat of fusion, $3.9 \pm 0.2 \mathrm{kcal} / \mathrm{mole}$. The uncertainties are estimated limits of error, based on internal consistency and on the values of the standards.
The authors express their sincere appreciation to Joan R. Rosenblatt of the Statistical Engineering Section, who was consulted on the statistical analysis of the data.

\section{References}

[1] L. Belladen, Il sistema $\mathrm{Bi}_{2} \mathrm{O}_{3}-\mathrm{PbO}$ (The System $\mathrm{Bi}_{2} \mathrm{O}_{3}-\mathrm{PbO}$ ), Gazz. chim. ital. 52, II, 160-164 (1922).

[2] K. K. Kelley, Contributions to Data on Theoretical Metallurgy: $V$, Heats of Fusion of Inorganic Substances, U.S. Bur. Mines Bull., No. 393, 166 pp. (1936); p. 26; Ceram. Abstr. 16 [5] 162 (1937).

[3] O. Kubaschewski and E. LL. Evans, Metallurgical Thermochemistry, 426 pp, 3d ed., rev. (Pergamon Press, New York, 1958).

[4] F. D. Rossini, D. D. Wagman, W. H. Evans, S. Levine, and I. Jaffee, Selected Values of Chemical Thermodynamic Properties, NBS Cir. 500, (1952) 1268 pp.

[5] E. M. Levin and C. L. McDaniel, The System $\mathrm{Bi}_{2} \mathrm{O}_{3}-\mathrm{B}_{2} \mathrm{O}_{3}$, J. Am. Ceram. Soc. 45 [8] 355-360 (1962).

[6] G. Gattow and H. Schröder, "Über Wismutoxide, III, Die Kristallstruktur der Hochtemperaturmodifikation von Wismut (III)-oxid $\left(\delta-\mathrm{Bi}_{2} \mathrm{O}_{3}\right)$ ", Z. anorg. allg. Chem. 318 [3-4] 176-189 (1962).

[7] G. Gattow and D. Schütze, Über Wismutoxide, VI, Über ein Wismut (III)-oxid mit höherem Sauerstoffgehalt ( $\beta$-Modifikation), Z. anorg. allg. Chem. 328, [1-2] 45-67 (1964).

[8] E. M. Levin and R. S. Roth, Polymorphism of bismuth sesquioxide. II. Effect of oxide additions on the polymorphism of $\mathrm{Bi}_{2} \mathrm{O}_{3}$, J. Res. NBS 68A (Phys, and Chem) No. 2, 197-206 (1964).

[9] W. J. Smothers and Yao Chiang, Differential Thermal Analysis: Theory and Practice, 444 pp (Chemical Publ. Co., Inc., New York, 1958).

[10] F. C. Kracek, The polymorphism of potassium nitrate, J. Phys. Chem. 34, 225-47 (1930).

[11] Isaac Barshad, Temperature and heat of reaction calibration of the differential thermal analysis apparatus, Am. Mineral. 37 [7\&8] 667-694 (1952).

[12] K. K. Kelley, Contributions to the Data on Theoretical Metallurgy. XIII. High-Temperature Heat-Content, HeatCapacity, and Entropy Data for the Elements and Inorganic Compounds, U.S. Bur. Mines Bull. 584, 1960. 232 pp.

[13] (a) Cavallaro, Atti Real. Acad. Ital., Rend. Class Sci., Fiz., Mat. et Nat. [4-5] 520-526 (1934). (b) F. E. Wittig, Z. Elektrochem. 54, 288 (1950). (c) W. Oelson, Arch. Eisenhüttenw. 28, 1-6 (1957).

[14] Ernest M.Levin and Robert S. Roth, Polymorphism of bismuth sesquioxide. I. Pure $\mathrm{Bi}_{2} \mathrm{O}_{3}$, J. Res. NBS 68A (Phys. and Chem.) No. 2, 189-195 (1964).

[15] C. J. Penther, S. T. Abrams, and F. H. Stross, Semi-automatic Thermal Analysis Apparatus, Anal. Chem. 23, 1459-66 (1951). 